\title{
Peripartum cardiomyopathy incidence and mortality in Sweden
}

\author{
Gustav Mattsson ${ }^{1} \odot$, Peter Magnusson ${ }^{1,2,3} \odot$ \\ ${ }^{1}$ Center for Research and Development, Uppsala University/Region Gävleborg, Gävle, Sweden \\ ${ }^{2}$ Cardiology Research Unit, Department of Medicine, Karolinska Institutet, Stockholm, Sweden \\ ${ }^{3}$ Faculty of Health and Occupational Studies, Department of Caring Sciences, \\ University of Gävle, Gävle, Sweden
}

Peripartum cardiomyopathy (PPCM) is a form of dilated cardiomyopathy with reduced ejection fraction that affects women late in pregnancy or the months following delivery [1]. It is a global disease with various geographical incidence and previously reported mortality across selected European centers was $4 \%$ at 6 -month follow-up and higher in other continents $[2,3]$. In the Danish population, the incidence of PPCM was 1:10 149 and at 1 year $3.3 \%$ had died [4]. The aim of this study was to examine long-term all-cause mortality in a Swedish nationwide cohort of patients with a history of PPCM.

This retrospective observational study included all patients who received the diagnosis of PPCM, International Classification of Diseases, tenth revision, (ICD-10) code O90.3, in The Swedish National Patient Register for both inpatient and outpatient specialist care episodes between 1997 and 2014 [5]. This was merged with data from the Swedish Cause of Death Register for the same time period. Data were described as frequencies, percentages, and means including standard deviations $( \pm)$. The Kaplan-Meier estimator was used to describe survival. The cumulative incidence of death was calculated using time to death as the censoring event; otherwise, total time of follow-up was used for patients who were still alive. The software program SPSS version 25 (IBM, Armonk, $\mathrm{NY}$ ) was used for analyses.

The sample consisted of 150 patients with the diagnosis of PPCM. The mean age at diagnosis was $34.6 \pm 6.3$ years and mean follow-up time $5.3 \pm$ \pm 4.29 years. Median year at the time of the diagnosis was 2010 , with an interquartile range of 5 years.
During the study period $5(3.3 \%)$ patients died from any cause. Kaplan-Meier estimated cumulative incidence of death was at 1-year $2.1 \%$, 3-years $3.2 \%, 5$-years $3.2 \%$, and at 10 -years $5.5 \%$. Figure 1 shows a Kaplan-Meier plot of estimated cumulative survival. Out of the 5 deaths, the main cause of death was cardiovascular disease in 4 cases and infectious disease in 1 case.

The National Board of Health and Welfare of Sweden provides data regarding the number of deliveries for the year 1997 up until 2014 [6]. Using these data the incidence of PPCM could be calculated for each year (Fig. 2). There was an increasing incidence of PPCM per 100,000 deliveries during the study period, ranging from 1.2 in 1997 up to 22.5 in 2012 , likely in part due to improved diagnostics and use of the ICD-10 code. In the Danish registry-based study the incidence was 1 in every 10,149 deliveries during the period 2005-2014 [4], the incidence in Sweden for the same period was 1 in every 11,014 deliveries.

The long-term prognosis of PPCM in the Swedish setting is good. Nevertheless, PPCM is a potentially life-threatening condition that requires careful attention in each individual case.

Conflict of interest: Gustav Mattsson has received speaker fee from Alnylam, Internetmedicin, and MSD; Peter Magnusson received speaker fees or grants from Abbott, Alnylam, Amicus Therapeutics, Bayer, AstraZeneca, BMS, Boehringer-Ingelheim, Coala Life, Internetmedicin, Lilly, MSD, Novo Nordisk, Octopus Medical, Pfizer, Vifor Pharma, and Zoll. No external financial support or funding was received for this study.

Address for correspondence: Gustav Mattsson, MD, Center for Research and Development, Uppsala University/Region Gävleborg, Gävle, SE-801 87, Sweden, tel: +46(0)703122296, e-mail: gustav.mattsson@regiongavleborg.se 


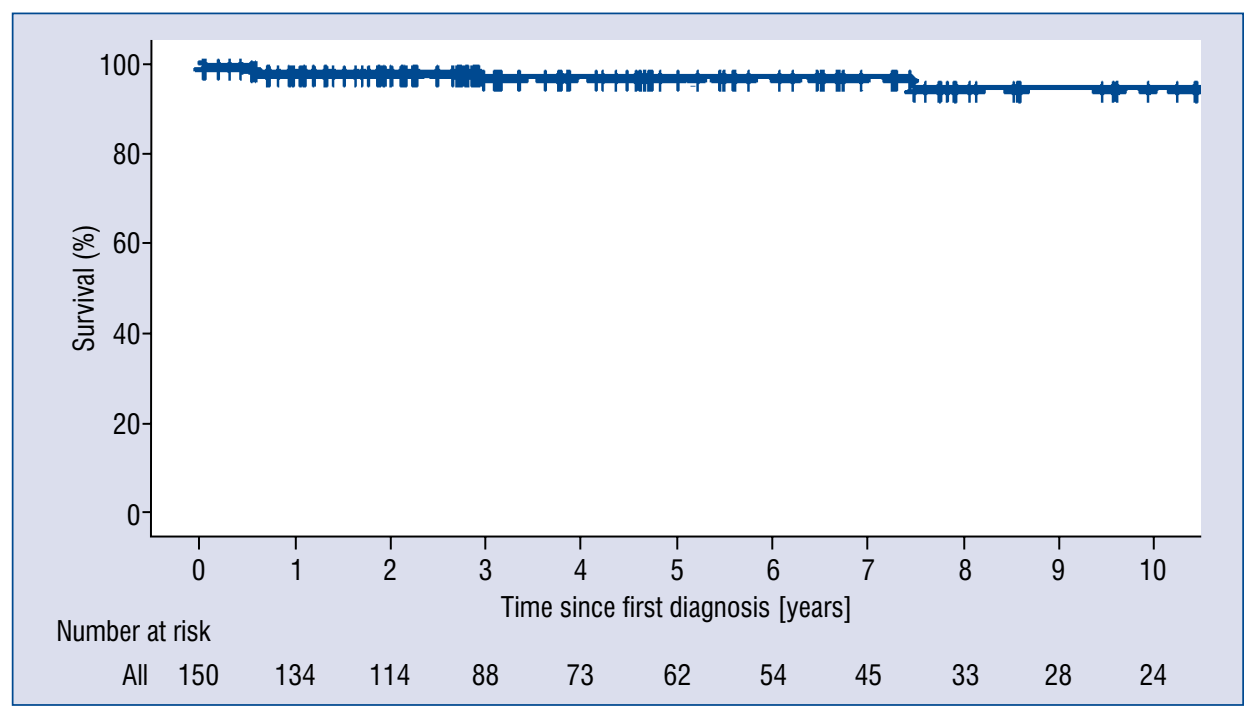

Figure 1. Kaplan-Meier estimate of cumulative survival for 150 patients with peripartum cardiomyopathy.

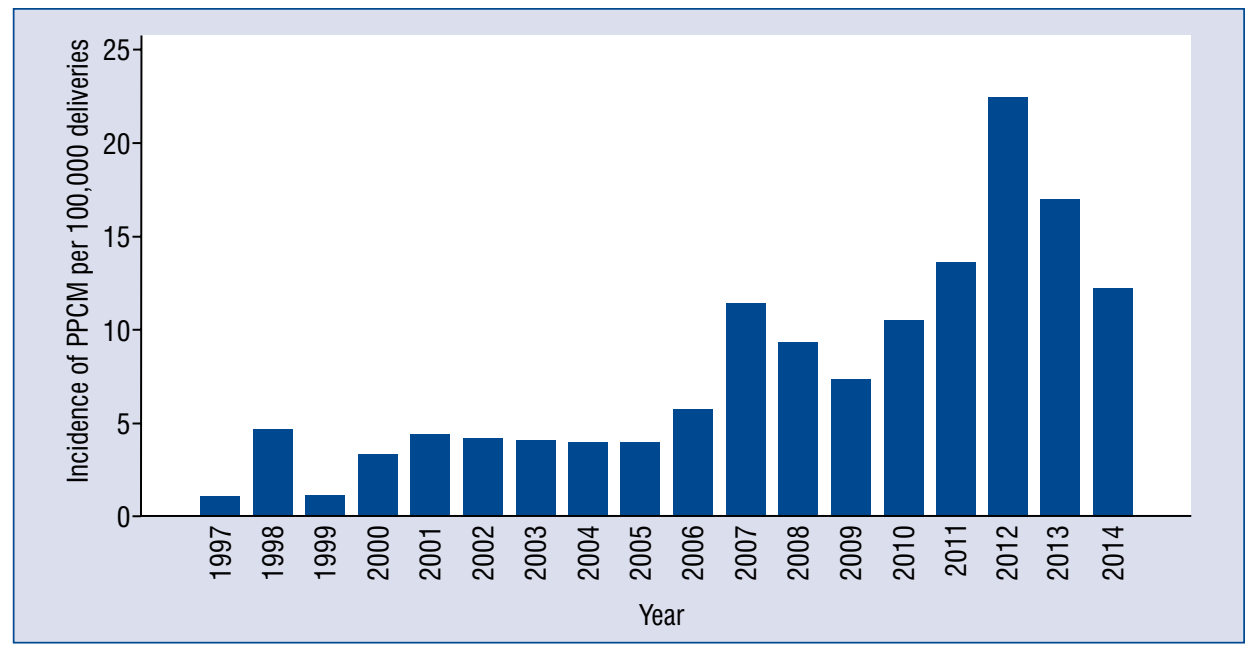

Figure 2. Incidence of peripartum cardiomyopathy (PPCM) diagnosis per 100,000 deliveries in Sweden for the years 1997-2014.

\section{References}

1. Bauersachs J, König T, van der Meer P, et al. Pathophysiology, diagnosis and management of peripartum cardiomyopathy: a position statement from the Heart Failure Association of the European Society of Cardiology Study Group on peripartum cardiomyopathy. Eur J Heart Fail. 2019; 21(7): 827-843, doi: 10.1002/ejhf.1493, indexed in Pubmed: 31243866.

2. Van Veldhuisen DJ, McMurray JJV, Bauersachs J. Clinical presentation, management, and 6-month outcomes in women with peripartum cardiomyopathy: an ESC EORP registry. Eur Heart J. 2020; 41(39): 3787-3797, doi: 10.1093/eurheartj/ehaa455, indexed in Pubmed: 32840318.

3. Sliwa K, Petrie MC, Hilfiker-Kleiner D, et al. Long-term prognosis, subsequent pregnancy, contraception and overall management of peripartum cardiomyopathy: practical guidance paper from the Heart Failure Association of the European Society of Cardiology Study Group on Peripartum Cardiomyopathy. Eur J Heart Fail. 2018; 20(6): 951-962, doi: 10.1002/ejhf.1178, indexed in Pubmed: 29578284.

4. Ersbøll AS, Johansen M, Damm P, et al. Peripartum cardiomyopathy in Denmark: a retrospective, population-based study of incidence, management and outcome. Eur J Heart Fail. 2017; 19(12): 1712-1720, doi: 10.1002/ejhf.882, indexed in Pubmed: 28597481.

5. Ludvigsson JF, Andersson E, Ekbom A, et al. External review and validation of the Swedish national inpatient register. BMC Public Health. 2011; 11: 450, doi: 10.1186/1471-2458-11-450, indexed in Pubmed: 21658213.

6. The National Board of Health and Welfare. Retrieved on the 26 of May 2021. https://www.socialstyrelsen.se/statistik-och-data/ statistik/statistikdatabasen/. 